\title{
Thoracic cage injury imaging in rugby players
}

\author{
Author: \\ Richard de Villiers ${ }^{1}$

\section{Affiliation:} \\ ${ }^{1}$ Drs Van Wageningen \\ and Partners, Somerset \\ West, South Africa \\ Correspondence to: \\ Richard de Villiers \\ Email: \\ rmldev@mweb.co.za \\ Postal address: \\ PO Box 317, Somerset \\ West 7129, South Africa \\ Dates: \\ Received: 05 May 2014 \\ Accepted: 04 Nov. 2014 \\ Published: 12 Dec. 2014 \\ How to cite this article: \\ De Villiers, R. Thoracic \\ cage injury imaging in \\ rugby players. S Afr J Rad. \\ 2014;18(2); Art. \#630, \\ 5 pages. http://dx.doi. \\ org/10.4102/sajr.v18i2.630

\section{Copyright: \\ (C) 2014. The Authors. Licensee: AOSIS \\ OpenJournals. This work is licensed under the Creative Commons} \\ Attribution License.
}

\section{Read online:}

Scan this QR
code with your
smart phone or
mobile device
to read online.

Rugby players often sustain high-impact collisions and are therefore at risk of significant traumatic thoracic injuries. Injury to the thoracic cage may be associated with potentially life-threatening sequelae. Player management is often based on the accuracy of the imaging report. The author suggests a combination of computed tomography and magnetic resonance imaging to optimally evaluate the full spectrum of these potentially serious injuries.

\section{Introduction}

Rugby players often sustain high-impact collisions and are therefore at risk of significant traumatic thoracic injuries. Furthermore, minimal gear is worn to protect the thoracic cage. In my experience, there have been significant changes in the physique of the modern-day rugby union player who, as a consequence of advanced fitness and nutritional programmes, is of superior strength, size and agility. This physique has resulted in an increase in the frequency of injuries as well as changes in the types of injury that we (Drs Van Wageningen and Partners) often encounter in our practice.

The thoracic cage protects the heart, lungs, trachea and large mediastinal vessels from injury. Injury to the thoracic cage may be associated with potentially life-threatening sequelae. Computed tomography (CT) and magnetic resonance imaging (MRI) are vital in the imaging of these potential injuries, especially as conventional radiography can often be falsely negative. Since the advent of professional sport, the roles of CT and MRI have been particularly relevant because decisions regarding player management are often based on the accuracy of the imaging report. This pictorial essay highlights (1) an imaging approach and (2) the relevant anatomy of the thoracic cage.

\section{Imaging approach}

Plain radiography is often not sufficient for the diagnostic assessment of thoracic cage injuries. High-resolution ultrasound (US) can assist in the diagnosis, but is limited by operator dependence and is also restricted to the visualisation of superficial structures. ${ }^{1}$ A combined CT / MRI protocol was developed at the author's institution - a private practice with a large sports injury referral base - in response to the low accuracy of conventional radiography and US in detecting thoracic cage injuries. The author's experience of thoracic cage injuries is in excess of 50 patients.

The patient is scanned in the prone position to decrease respiratory motion artifact. A single breath-hold acquisition or respiratory-gated acquisition is utilised for $\mathrm{CT}$, where possible, to minimise motion artifact arising from the patient's respiration. ${ }^{2}$ Patients should otherwise be advised to breathe gently following diaphragmatic excursions. ${ }^{3}$ For MRI, the patient is asked to breathe gently.

A standard large flex surface coil is used for MRI. An MRI-visible marker (Vitamin E capsule) is placed at the position of maximal tenderness. Axial T1 and short tau inversion recovery (STIR) sequences as well as coronal oblique T1 and STIR images (Figure 1) are obtained.

A non-contrast CT scan is performed and multiplanar reconstructions (MPR) and volume rendering technique (VRT) lead to optimal demonstration of the relevant pathology in most cases (Figure 2). Adjustment of CT window settings may be necessary (Figure 3). 


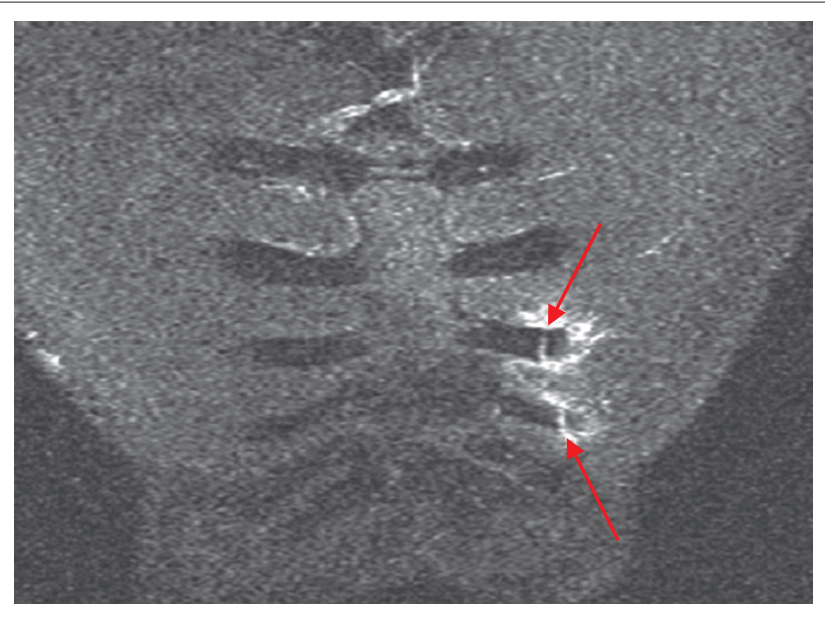

FIGURE 1: Coronal short tau inversion recovery (STIR) magnetic resonance imaging (MRI) of the chest wall demonstrates two undisplaced fractures (arrows) of the costochondral cartilage with surrounding soft-tissue oedema.

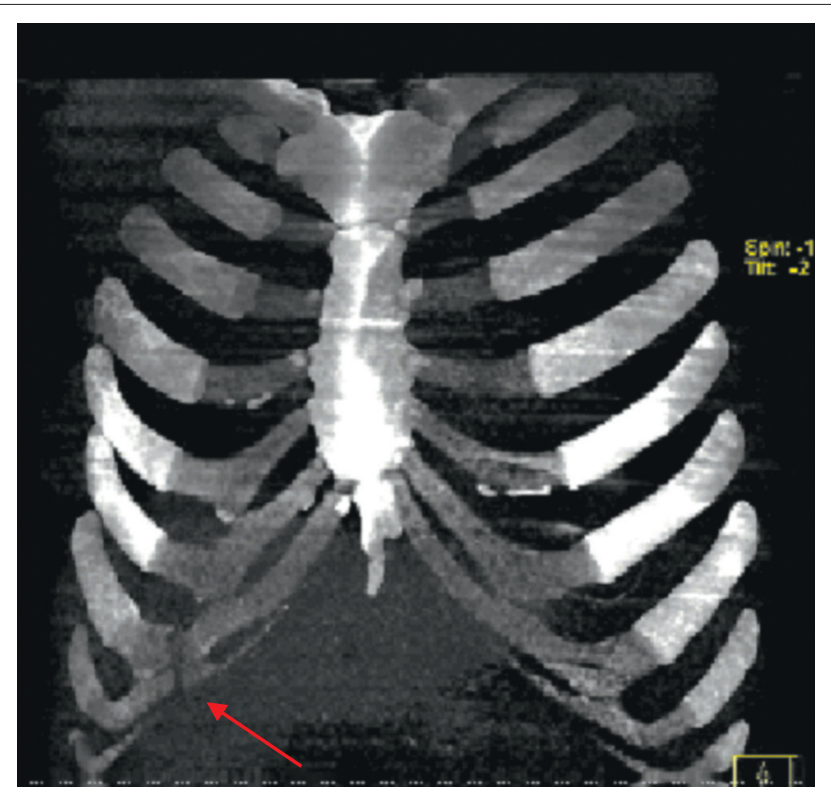

FIGURE 2: Computed tomography (CT) scan with volume rendering technique (VRT) view of the chest wall. Two minimally displaced costochondral fractures are demonstrated (arrow).

\section{Anatomy}

\section{Sternum, manubriosternal joint and xiphisternal joint}

The sternum comprises the body, manubrium and xiphoid process. It articulates with the clavicles and the cartilaginous portion of the first to seventh ribs, providing attachment sites for the sternocleidomastoid and pectoralis major muscles.

Sternal fractures are rare owing to the elastic recoil of the ribs, which suspend the sternum. ${ }^{4}$ A frontal impact may lead to sternal contusion, fracture and manubriosternal joint subluxation or dislocation (Figure 4). There may be an associated retrosternal haematoma (Figure 5). Associated cardiac injury is rare. ${ }^{5}$

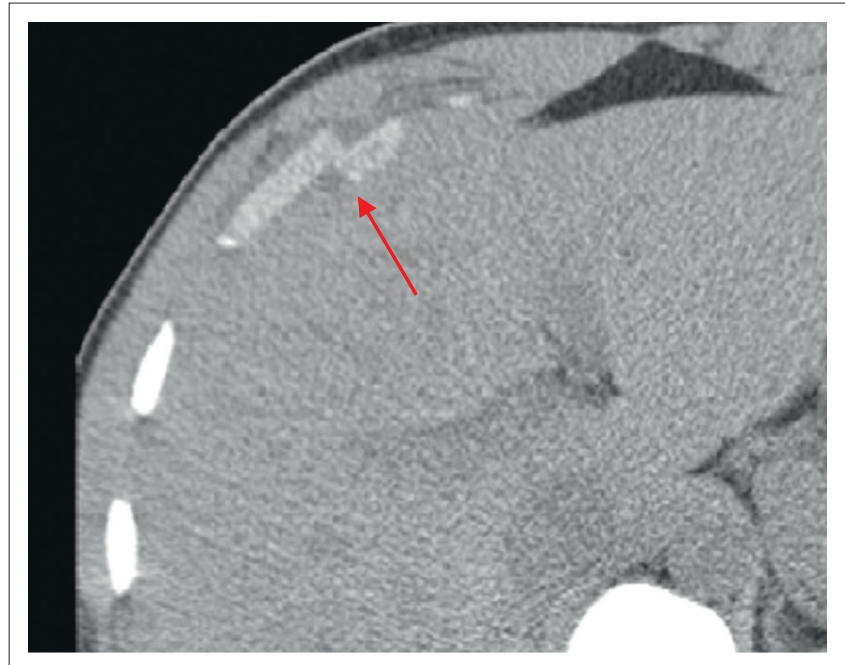

FIGURE 3: Axial computed tomography (CT) scan of the chest wall demonstrating a displaced fracture of the costochondral cartilage - an example of 'cartilage overlap' sign (arrow).

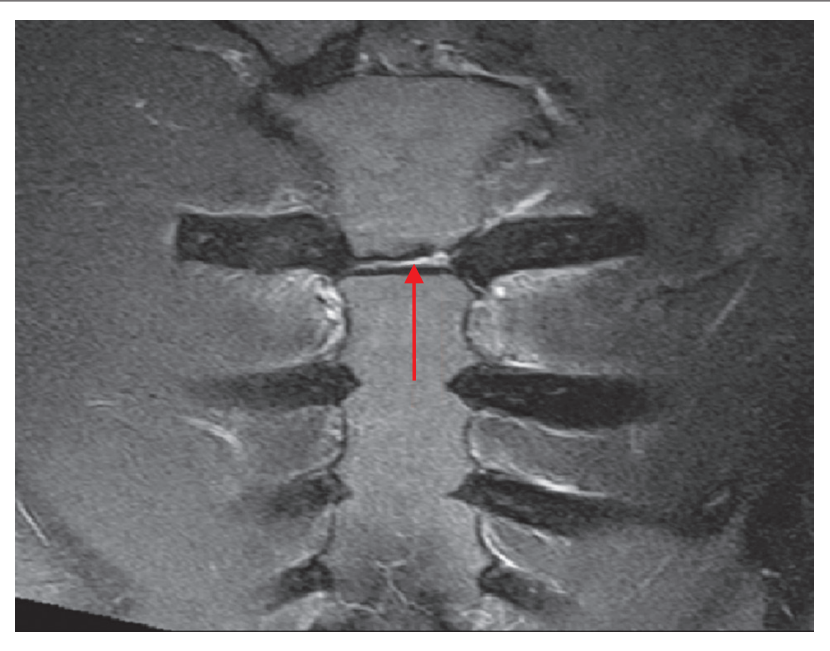

FIGURE 4: Coronal short tau inversion recovery (STIR) magnetic resonance imaging (MRI) of the sternum. There is a linear hyperintense signal in the manubriosternal joint in keeping with disruption of the manubriosternal synchondrosis (arrow). Note the intact sternocostal joints and costochondral cartilage.

\section{Sternoclavicular joint}

The sternoclavicular joint (SCJ) is a synovial joint that represents the only skeletal articulation between the axial skeleton and the upper limbs (Figure 6). ${ }^{6}$

Trauma to the sternoclavicular joint may cause a subluxation, dislocation and/or fracture of the medial clavicle or a fracture of the first costochondral cartilage (Figure 7). ${ }^{7}$ Posterior dislocations of the sternoclavicular joint are less common than anterior dislocations, with a reported incidence ranging between $5 \%$ and $27 \%$ of all SCJ dislocations. ${ }^{8}$ Posterior dislocation of the clavicle can cause potentially highly hazardous injuries owing to proximity to mediastinal vascular structures, the trachea and oesophagus (Figure 8). ${ }^{9}$ 


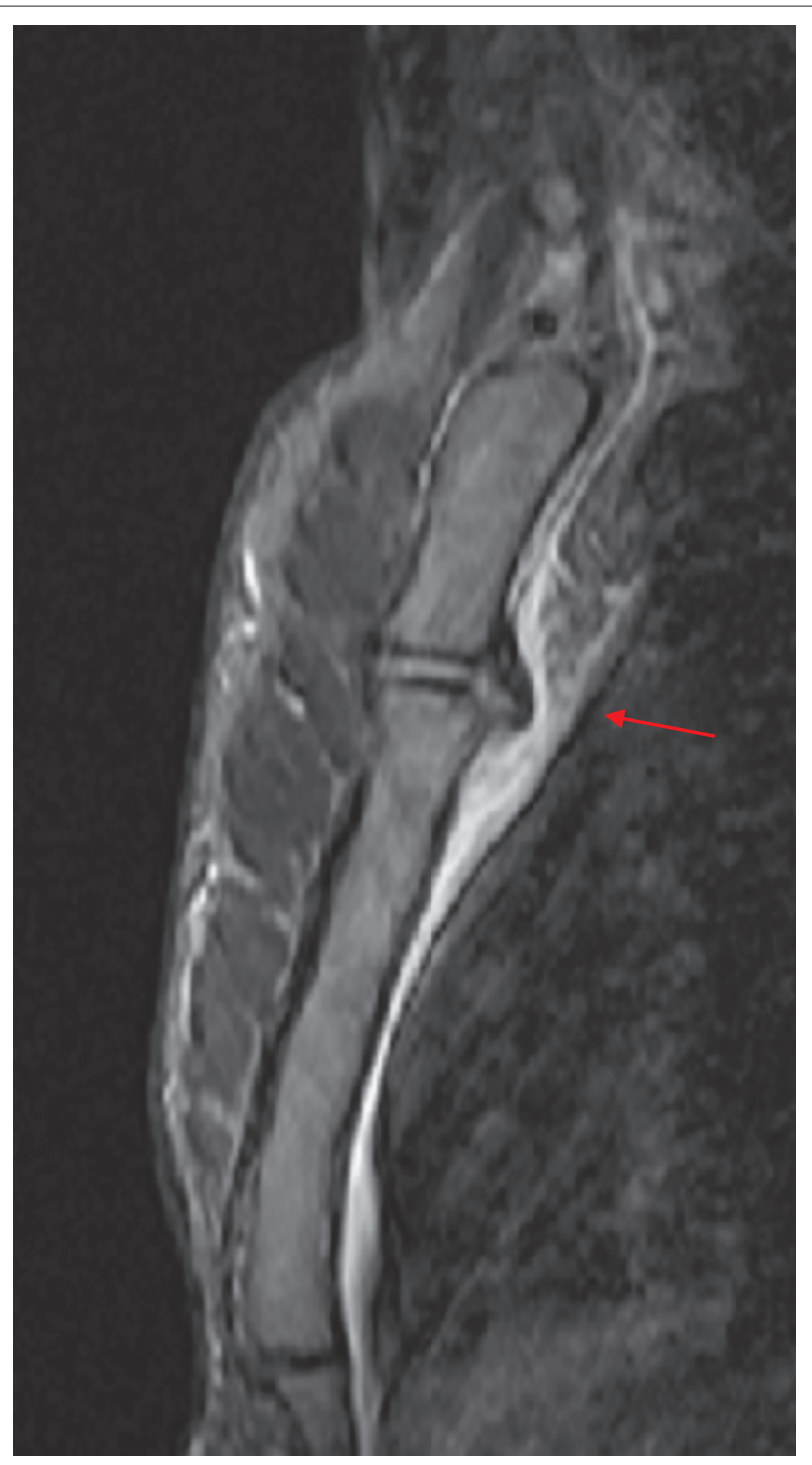

FIGURE 5: Sagittal short tau inversion recovery (STIR) magnetic resonance imaging (MRI) of the sternum showing hyperintense fluid posterior to the sternum in keeping with retrosternal haematoma. Note the associated stripping of the posterior periosteum (arrow).

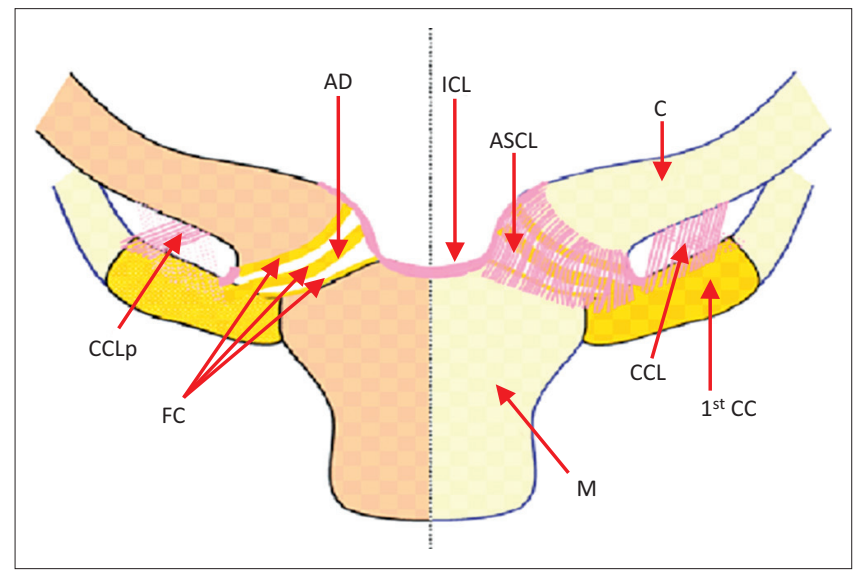

$\mathrm{AD}$, articular disc; $\mathrm{ASCL}$, anterior sternoclavicular ligament; C, clavicle; 1st $\mathrm{CC}$, first costal cartilage; CCL, costoclavicular ligament; CCLp, costoclavicular ligament posterior fibres; FC, fibrocartilage; IC, interclavicular ligament; $\mathrm{M}$, manubrium.

FIGURE 6: Schematic illustration of the sternoclavicular joint. The right joint is depicted as a coronal section through the clavicle, manubrium and first costal cartilage, whilst the left shows the intact joint.

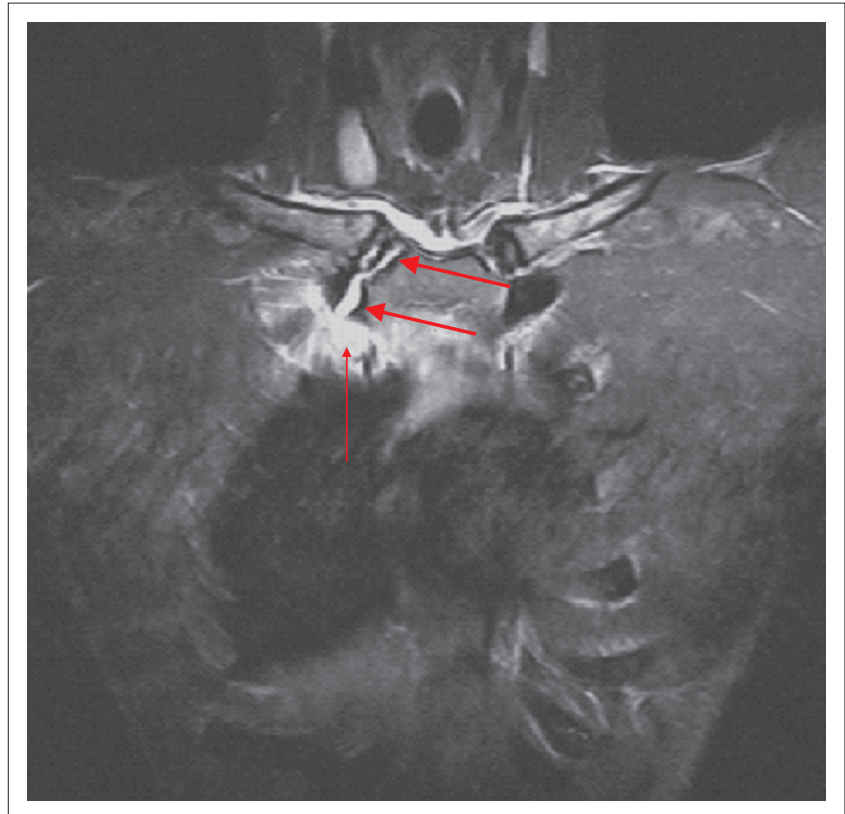

FIGURE 7: Coronal short tau inversion recovery (STIR) magnetic resonance imaging (MRI) of the manubriosternal joint demonstrates disruption of the sternoclavicular cartilage (larger two arrows) with surrounding haematoma (smaller arrow).

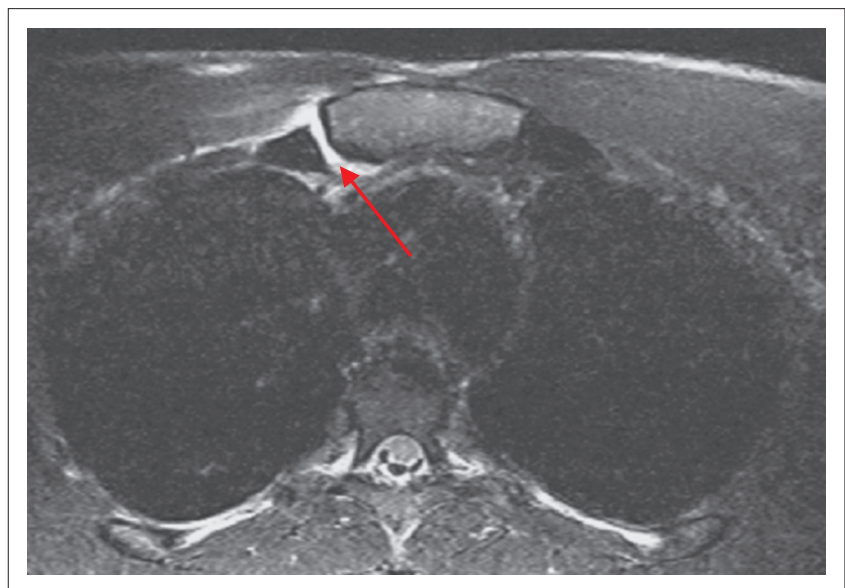

FIGURE 8: Axial short tau inversion recovery (STIR) sequence magnetic resonance imaging (MRI) of the sternocostal joint demonstrates fracture of the first sternocostal junction with posterior rib subluxation and surrounding haematoma (arrow)

\section{Ribs and associated joints}

The first to seventh ribs articulate with the sternum via the costal cartilages. The cartilages of the first to tenth ribs join the superjacent costal cartilage, whereas the eleventh and twelfth ribs have a free anterior end. The sixth to ninth costal cartilages articulate via a synovial joint with a fibrous capsule. These interchondral joints are strengthened by interchondral ligaments. Costal cartilages are connected to the ribs via the costochondral joints. Posteriorly, the head of the ribs articulate with the corresponding vertebral body to form the costovertebral joints. ${ }^{10}$

Rib fractures are often identified following a compressive force to the thorax. The typical site of fracture is at the weakest point, namely the angle of the rib. Costochondral injuries are often the result of direct trauma and usually involve the middle and 

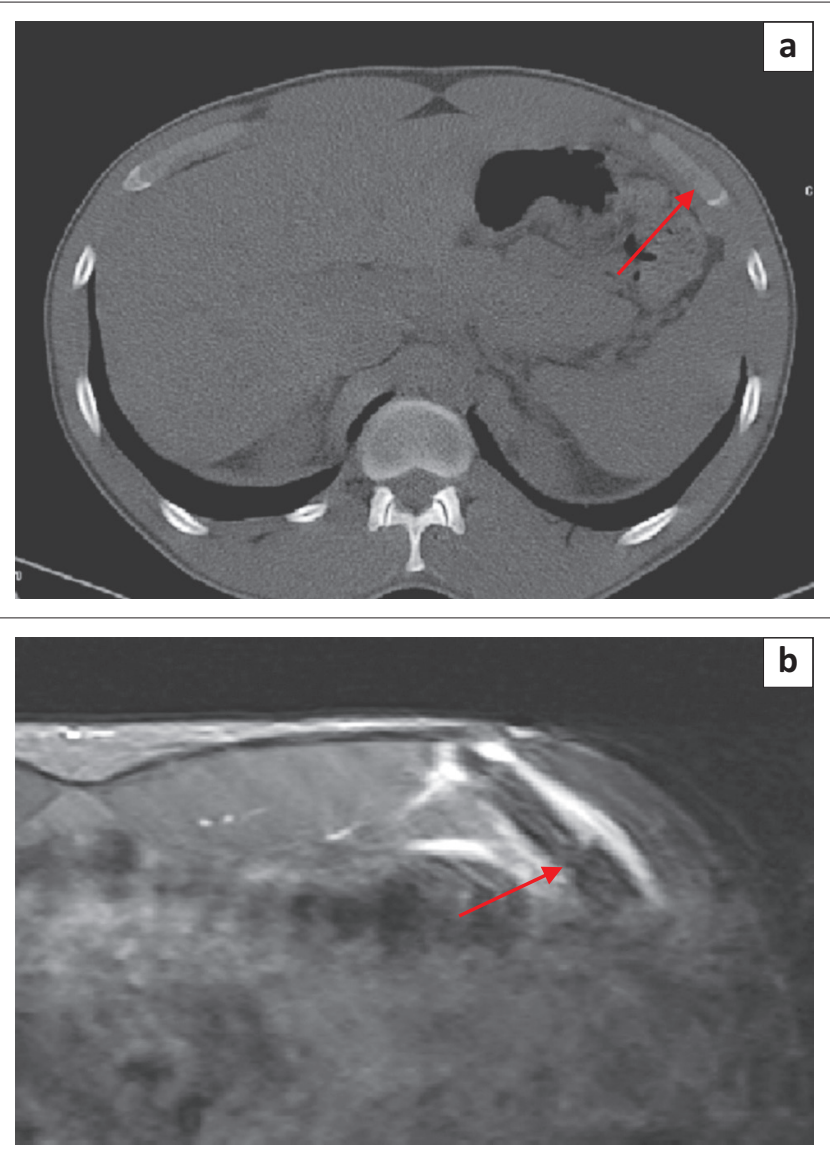

FIGURE 9: Axial computed tomography (CT) scan of the chest (a) shows a subtle costochondral cartilage fracture (arrow). Axial short tau inversion recovery (STIR) magnetic resonance imaging (MRI) (b) shows the fracture with surrounding haematoma (arrow). This type of injury can easily be missed and emphasises the need to perform both MRI and CT scans.

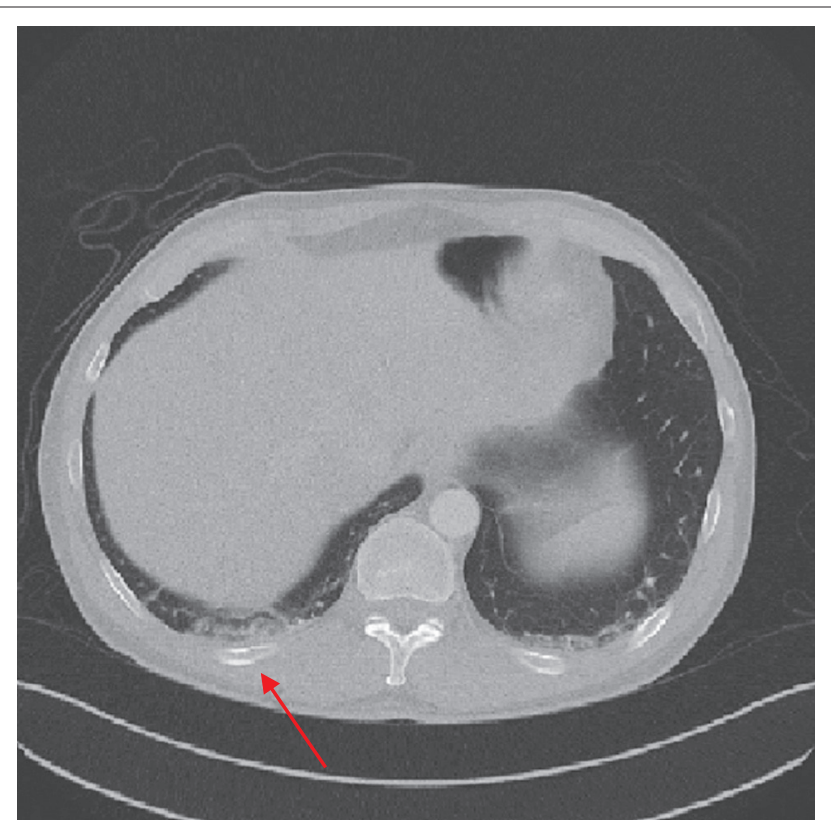

FIGURE 10: Computed tomography (CT) scan of the chest wall shows a minimally displaced posterior rib fracture (arrow).

lower ribs. ${ }^{11}$ These injuries may be missed or misdiagnosed and therefore US, CT and MRI play an important role in their diagnosis (Figure 9a, Figure 9b and Figure 10). ${ }^{12}$

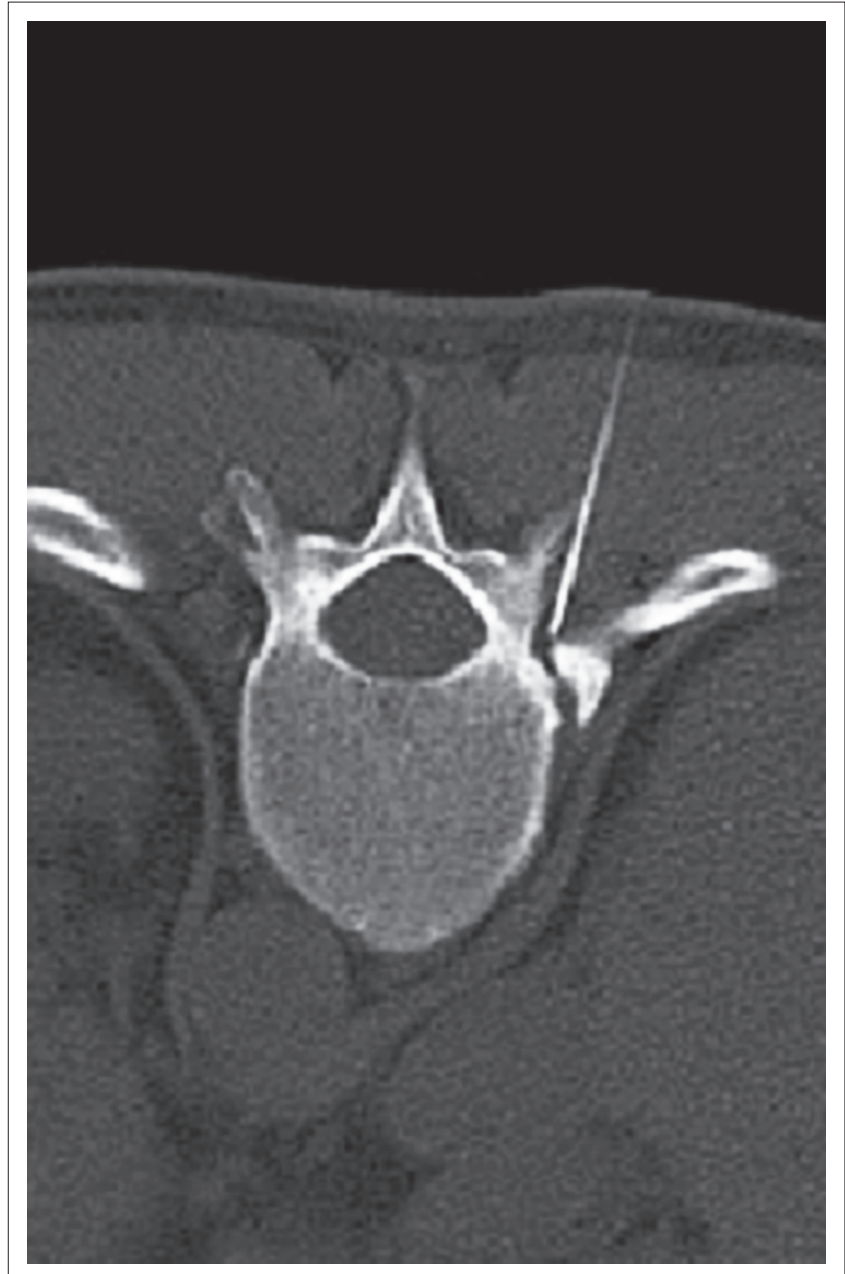

FIGURE 11: Computed tomography (CT) scan of the costovertebral joint demonstrating osteoarthrosis of the right costovertebral joint. There is subchondral sclerosis and osteophyte formation. A CT-guided intra-articular injection of the right costovertebral joint was performed, which gave instant pain relief.

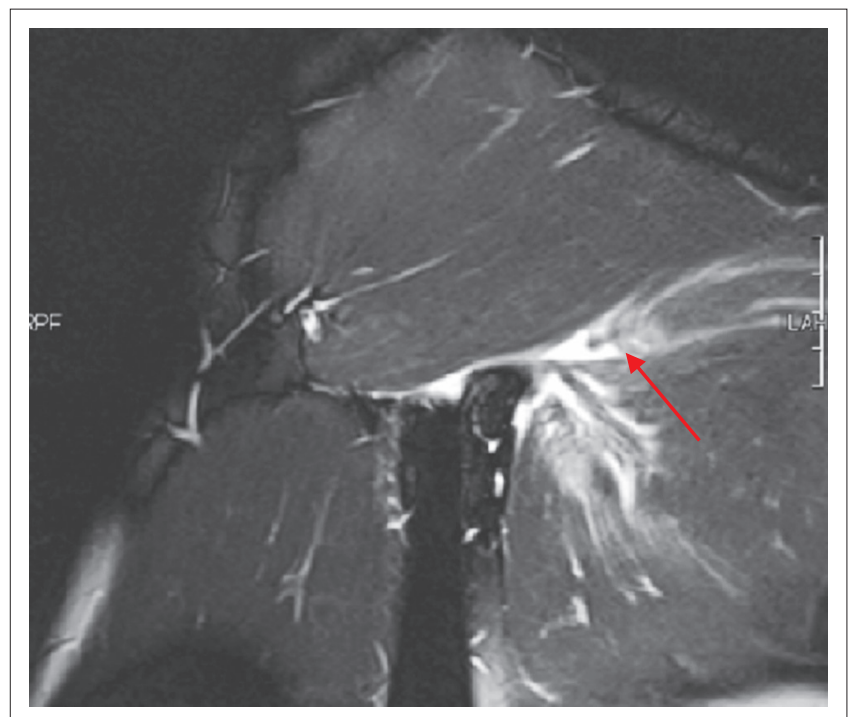

FIGURE 12: Axial T2 FS magnetic resonance imaging (MRI) of the pectoralis major muscle demonstrating a tear of the muscle, with tendon retraction and surrounding hyperintense haematoma (arrow).

CT-guided injections to the costovertebral and thoracic facet joints are administered to expedite return to activity (Figure 11). 


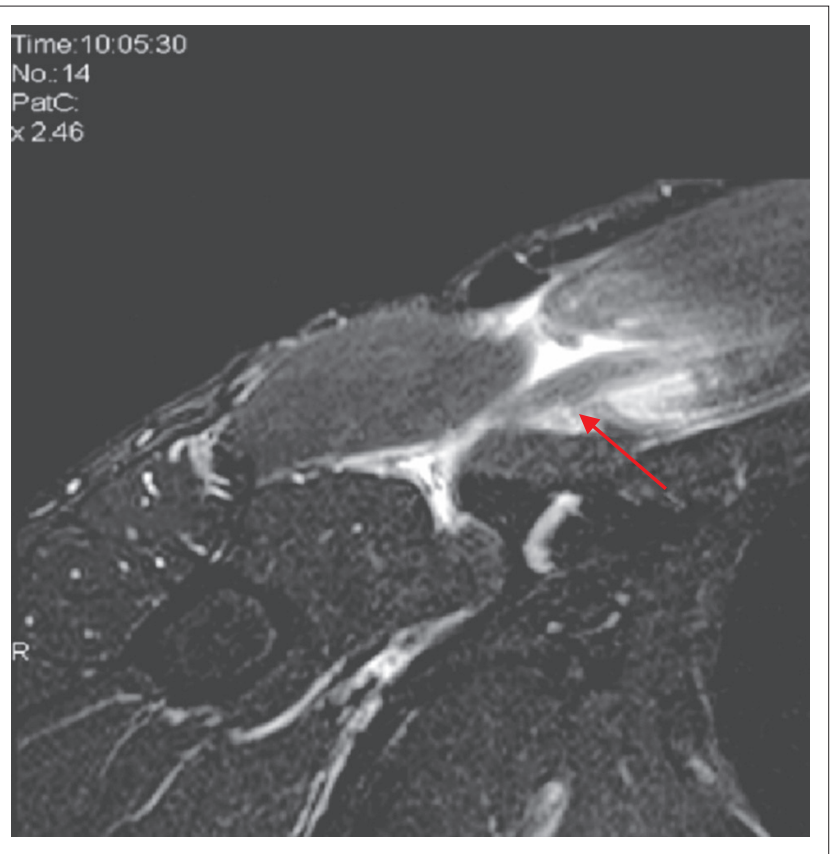

FIGURE 13: Coronal oblique short tau inversion recovery (STIR) magnetic resonance imaging (MRI) of the pectoralis major muscle. A tear of the pectoralis major tendon is noted with retraction (arrow) and surrounding haematoma.

\section{Muscle Injury}

The most common muscle injuries encountered at our institution involve the pectoralis major, rectus abdominus, transversus abdominus and oblique muscle groups. Pectoralis major muscle tears are observed at the sternal and/or clavicular heads, intramuscularly (Figure 12) at the musculotendinous junction (Figure 13), or may be at or near the humeral insertion..$^{13}$

\section{Conclusion}

Imaging plays a vital role in the prompt and accurate diagnosis of thoracic cage injuries. The author suggests a combination of CT and MRI to optimally evaluate the full spectrum of various injuries. A thorough knowledge of the relevant anatomy and pathology is essential in developing an approach to the imaging of potential thoracic cage injuries in the professional athlete.

\section{Acknowledgements}

Drs Daichi Hayashi and Frank Roemer are thanked for their contributions towards this article.

\section{Competing interests}

The author declares that he has no financial or personal relationships that might have inappropriately influenced him in writing this article.

\section{References}

1. WestcottJ, DavisS, Fleishon H, etal. Rib fractures. Radiology. 2000;215:Suppl.637-639.

2. Aslam M, Rajesh $A$, Entwisle J, et al. Pictorial review: MRI of the sternum and sternoclavicular joints. $\mathrm{Br} J$ Radiol. 2002;75(895):627-634. http://dx.doi. org/10.1259/bjr.75.895.750627

3. Hopper MA, Tirman P, Robinson P. Muscle injury of the chest wall and upper extremity. Semin Musculoskelet Radiol. 2010;14(2):122-130. http://dx.doi. org/10.1055/s-0030-1253156

4. Fowler AW. Flexion-compression injury of the sternum. J Bone Joint Surg Br. 1957;39B:487-497.

5. Crestanello JA, Samuels LE. Sternal fracture with mediastinal haematoma: Delayed cardiopulmonary sequelae. J Trauma. 1999;47(1):161-164. http://dx.doi. org/10.1097/00005373-199907000-00034

6. Johnson D. Section 6, pectoral girdle and upper limb. In: Standring S, editor. Gray's anatomy: The anatomical basis of clinical practice. 40th edn. London: Elsevier 2008:800-801.

7. Hayashi D, Roemer FW, Kohler R, Guermazi A, Gebers C, De Villiers R. Thoracic injuries in professional rugby players: Mechanisms of injury and imaging characteristics. $\mathrm{Br}$ J Sports Med. 2013. http://dx.doi.org/10.1136/bjsports-2013-092681

8. Gilot GJ, Wirth MA, Rockwood CA Jr. Injuries to the sternoclavicular joint. In Bucholz RW, Heckman JD, Court-Brown C, editors. Rockwood and Green's fractures in adults. 6th edn. Lippincott Williams \& Wilkins, 2006; p. 1365-1397.

9. Thomas DP, Davies A, Hoddinott HC. Posterior sternoclavicular dislocations-a diagnosis easily missed. Ann R Coll Surg Engl. 1999;81(3):201-204.

10. Gatzoulis MA. Section 7, thorax. In: Standring S, editor Gray's anatomy: The anatomical basis of clinical practice. 40th edn. London: Elsevier, 2008; p. 917-926.

11. Lopez V Jr, Ma R, Li X, Steele J, Allen AA. Costal cartilage fractures and disruptions in a rugby football player. Clin J Sport Med. 2013;23(3):232-234. http://dx.doi. org/10.1097/JSM.0b013e31825b55ed

12. Kemp SP, Targett SG. Injury to the first rib synchondrosis in a rugby footballer. $\mathrm{Br}$ J Sports Med. 1999;33(2):131-132. http://dx.doi.org/10.1136/bjsm.33.2.131

13. Connell DA, Potter HG, Sherman MF, Wickiewicz TL. Injuries of the pectoralis major muscle: Evaluation with MR imaging. Radiology. 1999;210(3):785-791. http://dx.doi.org/10.1148/radiology.210.3.r99fe43785 